\title{
Microbial Safety, Nutritive Value and Residual Pesticide Levels are Comparable among Commercial, Laboratory and Homemade Baby Food Samples - A Pilot Study
}

\author{
Simmer Randhawa ${ }^{1}$, Yukio Kakuda*,2, Christina L. Wong ${ }^{3}$ and David L. Yeung ${ }^{4}$ \\ ${ }^{1}$ Guelph Food Technology Centre, Guelph, Ontario, Canada \\ ${ }^{2}$ Department of Food Science, University of Guelph, Guelph, Ontario, Canada \\ ${ }^{3}$ Department of Nutritional Sciences, University of Toronto, Toronto, Ontario, Canada \\ ${ }^{4}$ H.J. Heinz Company, Toronto, Ontario, Canada
}

\begin{abstract}
Objective: Parents are often concerned about potential safety and nutritional differences between store-bought and homemade baby foods but research evaluating them is limited. Thus, samples from commercial, lab-made and homemade baby foods were analyzed in this pilot study to compare their microbial safety, nutritive value and residual pesticide levels.

Methods: Ten samples were collected per group, totalling thirty. Commercial samples were provided by a large-scale commercial manufacturer along with their corresponding recipes prepared in the laboratory and at home by ten different mothers in the Brampton and Guelph areas of Ontario, Canada.

Results: Except for zinc, samples produced commercially, at the lab and at home had comparable mean contents for total energy, fat, carbohydrate, protein, thiamine, riboflavin, vitamin C, calcium, and iron. Homemade samples had higher mean zinc content than commercial baby foods $(\mathrm{P}<0.05)$. Commercial samples had the lowest bacterial growth $(<5 \mathrm{Cfu} / \mathrm{g}$ total plate counts). However, all baby food samples were microbiologically safe. At least one sample from all three groups contained pesticide residues. Peaches in all the three groups tested positive for N-methyl carbamate screen (oxamyl or carbaryl). However, the levels of pesticide residues found in all baby food samples were below government maximum residue limits.

Conclusion: Baby foods prepared commercially, in the laboratory and at home are similarly safe and nutritious. When preparing them at home, extra care should nevertheless be taken to prevent contamination since slight negligence can lead to serious health complications for the baby. Replication of findings in other jurisdictions and with a larger sampling frame would strengthen the generalizability of the study findings.
\end{abstract}

Keywords: Infant Food, Pesticide Residues, Microbial Count, Nutritional Value, Commercial Foods, Homemade, Lab Made, Child Nutrition Sciences.

\section{INTRODUCTION}

The alimentary decisions parents make to feed their baby shapes the infant's present and future health status. For optimal health, exclusive breastfeeding is strongly encouraged for the first six months of life, with the introduction to complementary baby foods at 6 to $18-24$ months of age to facilitate the transition from exclusive breastfeeding to consumption of family foods [1]. Baby foods are typically pureed, strained or mashed. They include solids (i.e. cereals, fruits, vegetables) and fruit juices and exclude human milk and infant formula [2]. They were traditionally made at home until the more convenient ready-made baby foods appeared on the market over a century ago. Regardless of how baby

*Address correspondence to this author at the Department of Food Science, University of Guelph, Food Science Building 38, Guelph, Ontario, N1G 2W1, Canada; Tel: 519-824-4120, Ext: 52260;

Fax: 519-824-6631; E-mail: ykakuda@uoguelph.ca foods are prepared, they must be both nutritionally adequate and safe [2]. Very little data have been published on analyses of the content of baby foods and the little available have been very selective on reporting the content of very specific nutrients such as sodium [3] and carotenoids [4] or specific microbial [5-8] and chemical contaminants [9] in baby foods. However, there is no evidence of direct comparison of homemade and commercially prepared baby foods. The limited data available suggest differences exist in nutrient composition, microbial load and presence of pesticides of homeprepared baby foods when compared to commercial baby foods. Homemade baby foods are often perceived as being the optimal choice; however, it is currently unclear whether homemade baby foods are "better" for a child's wellbeing in terms of nutritional value, safety, and purity.

Despite baby foods being largely ignored by researchers, there is a pressing need for greater understanding of the safety and nutritional profiles of infant foods. Thus, owing to 
parental concerns and public health interests, this study compared the nutritive value, microbial safety and levels of pesticide residues in commercial, laboratory-made and homemade baby food samples. It was hypothesized that commercial products are microbiologically safe and have low amounts of pesticide residues but are less nutritious than both lab-made and homemade baby food products.

\section{MATERIALS \& METHODOLOGY}

\section{Baby Food Samples}

Ten different baby food samples were provided by the H.J. Heinz Company, Toronto, Canada, along with their corresponding recipes, which were used to make samples in the lab and at home. Ten baby food samples were prepared in the laboratory with ingredients purchased from local grocery stores in Guelph. Ten mothers with young infants from the Guelph and Brampton areas in Ontario, Canada were recruited, through referral by staff and students from the Department of Food Science at the University of Guelph, to provide the homemade versions of the manufactured products. The women were instructed to strictly follow the recipes provided by H.J. Heinz Company, which contained detailed cooking and storage instructions, but were not told about the objective of the study. Each mother prepared one of the provided recipes.

All the samples $(\mathrm{n}=30)$ were homogenized and stored in clear labeled sterile plastic bottles. They were kept frozen and sent to the Laboratory Services Division, University of Guelph, Ontario, Canada, for analysis.

\section{Outcome Measures}

In total, thirty samples were analyzed for nutrition, microbial load and pesticide residues.

\section{Nutrition}

Proximate analysis was conducted to determine energy, protein, fat, carbohydrate, vitamin $\mathrm{A}$, vitamins $\mathrm{C}$, thiamin, niacin, riboflavin, iron, calcium and zinc content of the samples [10].

\section{Microbiology}

For microbial load, total plate counts [11], yeast and mould [12], E.coli [13], salmonella [14], Staphylococcus aureus [15], Bacillus cereus [16], Clostridium perfringens [17], Listeria monocytogenes [18], verotoxin producing E.coli (VTEC) [19] and coliforms [13] were measured in all samples through analytical methods as described in Health Canada's "The Compendium of Analytical Methods: Official Methods for the Microbiological Analysis of Foods".

\section{Pesticide Residues}

Analytical methods were described previously by Fillion et al. [20]. Briefly, N-methyl carbamate, organochlorine, organonitrogen and organophosphorus screen tests were performed and when positive, assays to detect individual pesticides were performed. Measures for microbiology and nutrition were performed on all samples whereas pesticide residues were measured only in apple sauce, peaches, carrots and sweet potatoes across all three groups.

\section{Statistical Analysis}

All statistics were performed with SPSS v14.0. One-way ANOVA were used to identify differences among commercial, lab and homemade baby food samples. Significance was set at $\mathrm{P}<0.05$.

\section{RESULTS}

\section{Nutritional Profile}

Homemade and lab-made baby food samples derived $80 \%$ and $87 \%$ of their total energy from carbohydrates and protein, whereas calories in commercial samples came from carbohydrates and fat (78\%), (Table 1). Average thiamine, riboflavin, vitamin $\mathrm{C}$, iron and calcium contents were comparable among the three groups of baby food samples $(\mathrm{P}>0.05)$ (Table 1). None of the commercial samples contained detectable amounts of vitamin $\mathrm{C}$; whereas 2 lab-made samples (peaches and Spanish chicken with rice) had 20.7 and $7.9 \mathrm{mg}$ of vitamin C per $100 \mathrm{~g}$. Three out of ten homemade baby food samples (peaches; chicken in broth; Spanish chicken with rice) contained $23.2 \mathrm{mg}, 4.9 \mathrm{mg}$ and $7.3 \mathrm{mg}$ of vitamin C per $100 \mathrm{~g}$, respectively. Average zinc content in homemade samples $(12.38 \mu \mathrm{g} / \mathrm{g})$ was higher than in commercial samples $(3.96 \mu \mathrm{g} / \mathrm{g}),(\mathrm{P}=0.04)$.

\section{Microbiological Profile}

All thirty samples tested negative for Bacillus cereus, Clostridium perfringens, Listeria monocytogenes, Salmonella and VTEC (Table 2). Likewise, all the commercial, laboratory and homemade samples contained E.coli petrifilm counts under 5 colony forming units $(\mathrm{Cfu}) / \mathrm{g}$; yeast and mould counts un-der $50 \mathrm{Cfu} / \mathrm{g}$; and Staphylococcus aureus counts under $25 \mathrm{Cfu} / \mathrm{g}$. However, samples made at home had a higher mean total plate count or aerobic colony count than those made at the lab, which in turn had a higher mean than those commercially-produced $(\mathrm{P}<0.05)$. All ten commercial samples had $10 \mathrm{Cfu} / \mathrm{g}$ or less of total plate counts compared to three and one out of ten of the laboratory and homemade samples, respectively. The total plate counts for the remaining seven lab-made averaged $3150 \mathrm{Cfu} / \mathrm{g}$, while the nine homemade samples averaged $5310 \mathrm{Cfu} / \mathrm{g}$. Similarly, the mean coliform count was highest for homemade samples followed by lab-made samples and both had a higher mean than commercial samples $(\mathrm{P}<0.05)$. All ten commercial samples had less than $5 \mathrm{Cfu} / \mathrm{g}$ of coliform counts compared to six and five out of ten of the lab- and homemade samples, respectively. The coliform counts for the other four lab-made samples averaged $385 \mathrm{Cfu} / \mathrm{g}$ whereas, the remaining five homemade samples had the highest mean coliform count at $390 \mathrm{Cfu} / \mathrm{g}$.

\section{Pesticide Residues}

Table 3 lists the results of the pesticide residue analyses for the four types of fruits and vegetables tested (apple sauce, peaches, carrots and sweet potatoes) across the three groups. At least one sample from all three groups contained pesticide residues, with homemade containing the fewest (one sample) and the lab-made group having the maximum of three contaminated samples. In all, four pesticides were detected: 
Table 1. The Nutrition Composition of Baby Food Samples from all Groups Per 100 g *

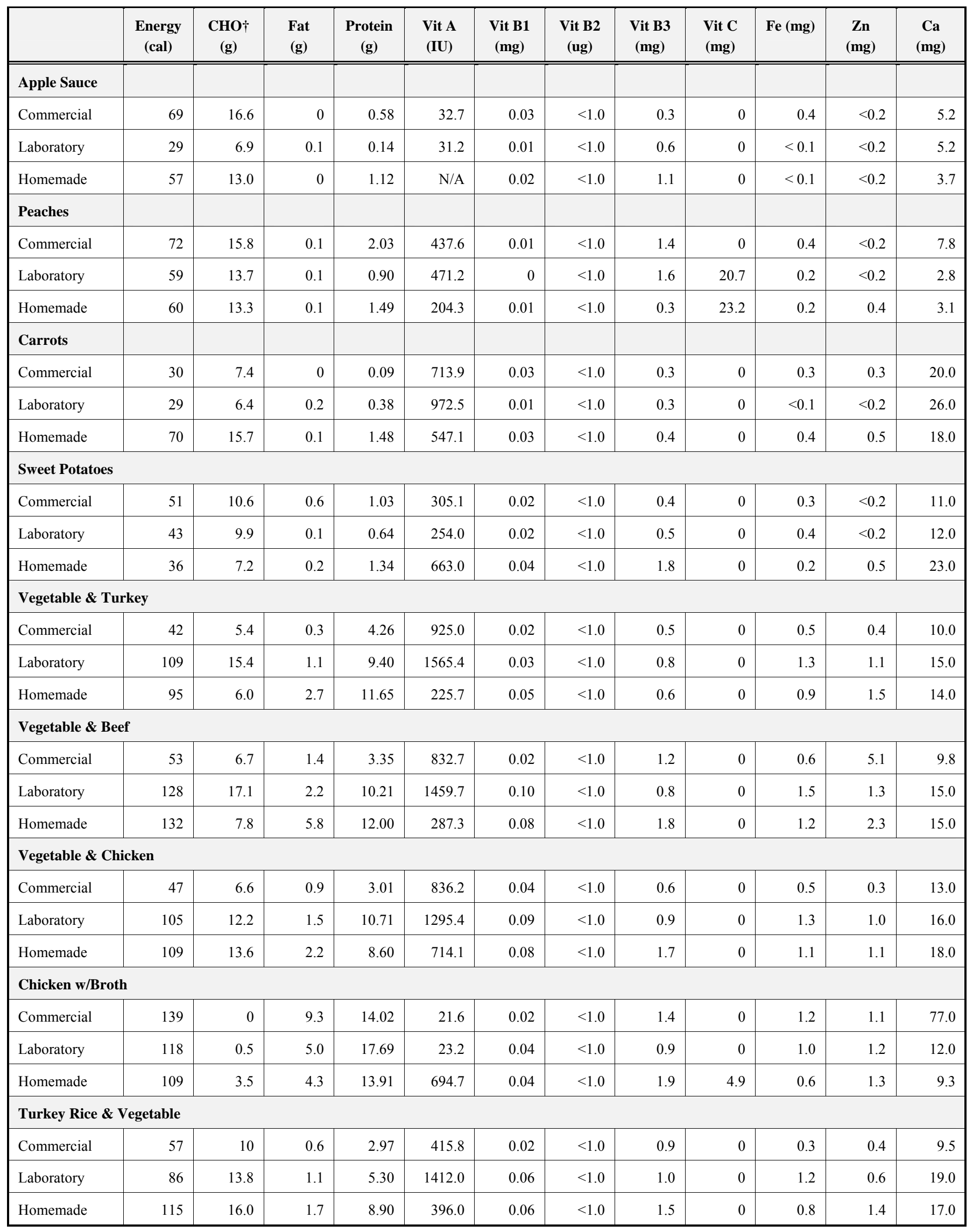


Table 1. Contd.....

\begin{tabular}{|c|c|c|c|c|c|c|c|c|c|c|c|c|}
\hline & $\begin{array}{c}\text { Energy } \\
\text { (cal) }\end{array}$ & $\begin{array}{c}\mathrm{CHO} \dagger \\
\text { (g) }\end{array}$ & Fat (g) & $\begin{array}{l}\text { Protein } \\
\text { (g) }\end{array}$ & $\begin{array}{l}\text { Vit A } \\
\text { (IU) }\end{array}$ & $\begin{array}{c}\text { Vit B1 } \\
\text { (mg) }\end{array}$ & $\begin{array}{c}\text { Vit B2 } \\
\text { (ug) }\end{array}$ & $\begin{array}{c}\text { Vit B3 } \\
\text { (mg) }\end{array}$ & $\begin{array}{l}\text { Vit C } \\
\text { (mg) }\end{array}$ & $\mathrm{Fe}$ (mg) & $\begin{array}{c}\mathrm{Zn} \\
\text { (mg) }\end{array}$ & $\begin{array}{c}\text { Ca } \\
\text { (mg) }\end{array}$ \\
\hline \multicolumn{13}{|c|}{ Spanish Chicken w/Rice } \\
\hline Commercial & 81 & 12.3 & 2.1 & 3.20 & 80.7 & 0.04 & $<1.0$ & 1.1 & 0 & 0.5 & 0.3 & 25.0 \\
\hline Laboratory & 86 & 16.0 & 0 & 5.49 & 277.9 & 0.06 & $<1.0$ & 0.5 & 7.9 & 1.5 & 0.6 & 18.0 \\
\hline P-value § & 0.30 & 0.64 & 0.73 & 0.29 & 0.12 & 0.17 & - & 0.07 & 0.36 & 0.16 & 0.04 & 0.63 \\
\hline
\end{tabular}

Abbreviations: $\mathrm{CHO}=$ Total carbohydrate (available carbohydrate + fibre); Vit = Vitamin; Vit B1 = Thiamin or Vitamin B1; Vit B2 = Riboflavin or vitamin B2; Vit B3 = Niacin or Vitamin B3; Fe = Iron; Zn = Zinc; Ca = Calcium; N/A = Not Available

$\dagger$ Composition of the baby food samples were determined by proximate analysis. $\mathrm{CHO}$ calculated by difference.

$\S$ P-value for the detection of differences among 10 commercial, 10 lab-made and 10 homemade baby food samples

Table 2. Results for the Microbial Analyses for Baby Samples for All Groups *

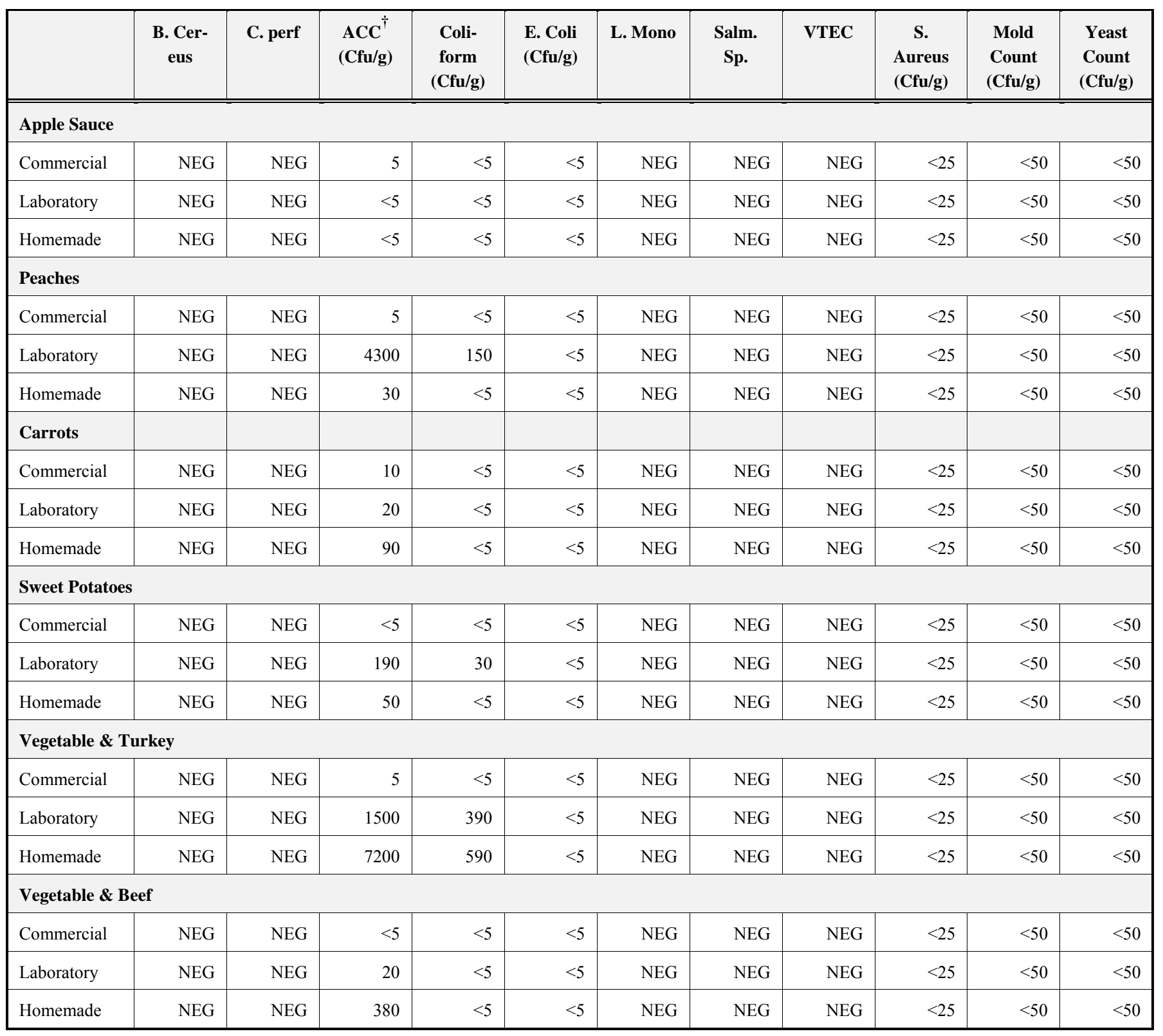


Table 2. Contd.....

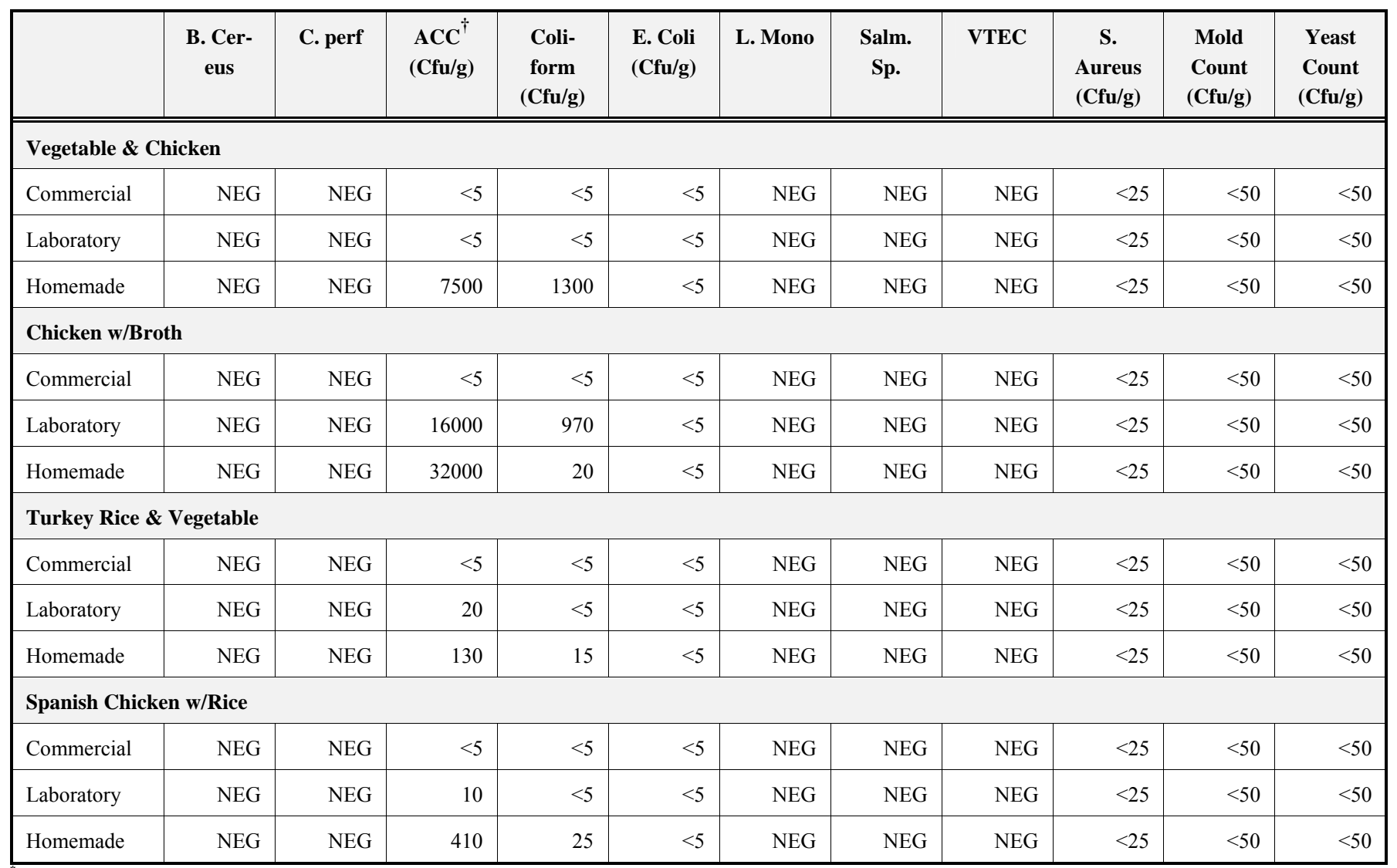

*Abbreviations: B. cereus $=$ Bacillus cereus; $\mathrm{C}$. perf $=$ Clostridium perfringens; $\mathrm{ACC}=$ Aerobic colony count; $\mathrm{L}$. mono $=$ Listeria monocytogenes; Salm. Sp. $=$ Salmonella species; S . aureus $=$ Staphylococcus aureus; VTEC $=$ Verocytotoxigenic escherichia coli

$\dagger$ Aerobic colony count represents total plate count as referred to in the text of this article.

$0.035 \mu \mathrm{g} / \mathrm{g}$ oxamyl (n-methyl carbamate) in commercial peaches; $0.14 \mu \mathrm{g} / \mathrm{g}$ permethrin (organochlorine) in commercial peaches; 0.054 and $0.05 \mu \mathrm{g} / \mathrm{g}$ dichloran (organochlorine) in commercial and lab-made sweet potatoes; and $0.22,0.11$ and $0.58 \mu \mathrm{g} / \mathrm{g}$ carbaryl (n-methyl carbamate) in lab-made peaches, homemade peaches and lab-made carrots, respectively. The amounts of residues found in all baby food samples fell below Canadian federal maximium residue levels (MRLs) established for oxamyl $(0.1 \mu \mathrm{g} / \mathrm{g})$, permethrin (1 $\mu \mathrm{g} / \mathrm{g})$ dichloran $(5 \mu \mathrm{g} / \mathrm{g})$ and carbaryl $(5 \mu \mathrm{g} / \mathrm{g})$ [21]. None of the samples tested positive for organonitrogen, organochlorine or organophosphorus screens.

\section{DISCUSSION}

The present pilot study evaluated baby foods prepared at home, in the laboratory and by a large-scale manufacturer for potential differences in microbial safety, nutritional profile and pesticide residue content. Contrary to the hypothesis, the findings showed that baby foods purchased from supermarkets, made in the lab or prepared at home are comparable to each other (Table 1). All samples of the commercial products were microbiologically safe and nutritionally similar to laband homemade baby foods (Table 1 and 2). Zinc was the only nutrient that was significantly lower in commercial samples than homemade samples (Table 1). In addition, the pesticide residues found in all three groups were below federally set maximum residue limits (MRL) (Table 3 ).
With respect to nutrition, homemade baby foods are not necessarily more nutritious than commercial baby foods because much depends on the recipes followed and raw ingredients used amongst other factors (Table 1). By having mothers and lab technicians use the recipes provided by the commercial manufacturer, this study ensured that the three groups of baby food samples used the same types of ingredients. Samples were also similar in their vitamin and mineral values except for zinc. Slight variations in nutrient content may have arisen from the use of different ingredient cultivars or varieties and growth conditions (i.e. climate, geography, and soils). If the parent prepares food in a nutritionconscious manner (i.e. leaving out added sugars and fats) and employs nutrient-preserving methods, then baby foods prepared at home will most likely be nutritious and wellbalanced for the infant. Likewise, some manufacturers may improve the nutritional quality of their products by eliminating added-sugars and fillers, which have become a growing concern for parents wishing to avoid purchasing infant foods with these ingredients [22].

Based on the microbiological assays, all thirty of the baby food samples were safe for consumption (Table 2). However, commercial baby food samples were the cleanest given their lowest bacterial activity, indicating that they were prepared under strict regulations for hygiene during the manufacturing process. On the other hand, some lab- and homemade samples had measurable total plate counts and coliforms, with homemade samples having the highest mi- 
Table 3. Traces of Pesticide Residues Detected Among All Groups of Baby Food Samples * +

\begin{tabular}{|c|c|c|c|c|}
\hline & Oxamyl (ug/g) & Permethrin (ug/g) & Dichloran (ug/g) & Carbaryl (ug/g) \\
\hline Laboratory & N/A & N/A & N/A & N/A \\
\hline Homemade & N/A & N/A & N/A & N/A \\
\hline \multicolumn{5}{|l|}{ Peaches } \\
\hline Commercial & 0.035 & 0.14 & N/A & N/A \\
\hline Laboratory & N/A & N/A & N/A & 0.22 \\
\hline Homemade & N/A & N/A & N/A & 0.11 \\
\hline \multicolumn{5}{|l|}{ Carrots } \\
\hline Homemade & N/A & N/A & N/A & N/A \\
\hline \multicolumn{5}{|c|}{ Sweet Potatoes } \\
\hline Commercial & N/A & N/A & 0.054 & N/A \\
\hline Laboratory & N/A & N/A & 0.05 & N/A \\
\hline Homemade & N/A & N/A & N/A & N/A \\
\hline \multicolumn{5}{|c|}{ Federal Maximum Residue Limits [21] } \\
\hline
\end{tabular}

None of the samples tested positive for organonitrogen or organophosphorus screens. When samples tested positive for the carbamate screen, individual assays for oxymyl and carbaryl were performed. When organochlorine screen tested positive, individual assays for dichloran and permethrin were performed.

${ }^{\dagger} \mathrm{N} / \mathrm{A}=$ not analyzed

${ }^{\S}$ When there was no MRL for the pesticide of interest in sweet potato roots, MRL for potatoes were used.

${ }^{\phi}$ Since there is no MRL for oxamyl residues in peaches, we compared the oxamyl residues in peaches against the established MRL for potatoes.

crobial load. These detectable total plate counts and coliform presence may signal poor hygiene and sanitary practices of the mothers at home and person(s) that made the baby food samples in the laboratory (i.e. fecal contamination). Another possible cause may have been that the raw ingredients used in these samples were purchased contaminated (i.e. coliforms in growing soil) and were not properly processed or adequately washed. This finding highlights that foods prepared in a less tightly regulated environment may promote the growth of bacteria leading to food spoilage and food-borne illnesses. Canadian commercial baby food manufacturers have quality control systems that rigorously monitor personnel sanitation at all stages during production and therefore it is the storage and handling of commercial baby foods, after they are opened, that will determine their safety. Health officials must therefore continue underscoring to caregivers that strict hygiene practices must be followed and ingredients need to be processed and heated accordingly before feeding babies. In this manner, the home kitchen will fall within nec- essary standards for making safe baby food that will be comparable to commercially-made products; exposing infants to a lower risk of contamination and illness.

It is important to note that the pesticide residues detected (carbaryl, oxamyl, permethrin, and dichloran) are permitted for use in Canada and the amounts present in the study samples were below federal MRLs, demonstrating that the baby foods from all three preparation groups were safe for consumption (Table 3) [21]. MRLs are derived from supervised field trials performed according to good agricultural practices (i.e. used under intended conditions of agricultural use) [23]. Ideally, risk assessment of pesticides should be based on acceptable daily intake (ADI) values, which indicate the level of exposure that could be taken every day throughout life. The ADI for carbaryl, oxamyl, permethrin and dichloran are $0.008,0.009,0.05$ and $0.01 \mathrm{mg} / \mathrm{kg} / \mathrm{d}$ respectively [24]. Since we did not assess intake or have access to regional or national intake data to determine potential intakes, we relied 
on MRL's. As mentioned earlier, all pesticides analyzed are approved for use in Canada and the approval process requires demonstrating that potential intakes in Canada at MRL levels do not exceed the ADI. The dietary risk assessment takes into account the fact that different segments of the population (i.e., infants, toddlers, children, adolescents and adults) have different eating habits $[25,26]$.

The results of the present study suggests that the type and number of pesticide residues vary across ingredients. The samples from peach baby foods in all three groups contained 3 out of 4 of the residues detected: carbaryl, oxymal and permethrin. Carbaryl (1-naphthyl methylcarbamate), a popular insecticide used in home gardens and commercial agriculture, is classified as a likely human carcinogen [27]. While oxamyl, another n-methyl carbamate, is considered to be extremely poisonous to humans and acute oral exposure may cause death [28]. Another study has also found peaches to be more likely to contain at least two different pesticide residues and have very high toxicity indices compared to other fruits and vegetables [29], perhaps reflecting the different practices employed in peach crop management. Commercial and lab-made sweet potatoes contained traces of dichloran, a moderately toxic fungicide and post-harvest sprout inhibitor that could easily be replaced with refrigeration [30]. Despite having residues levels below Canadian federal limits, concerned parents may still want to take additional steps in reducing their child's risk to the unknown health and developmental ramifications of pesticides. Feeding babies a variety of foods is an effective means of reducing repetitive exposure of the same residues [31]. Some parents may choose to buy commercial baby foods made from organically-grown produce; however, evidence suggests that organic baby food is not lower in pesticide residues than non-organic [9]. This can be largely explained by routine food handling practices such as washing, peeling and cooking during the production of commercial baby food, making the difference between organic and conventional baby food negligible [32,33]. If a parent chooses to make foods at home, caregivers should rigorously wash or peel raw ingredients especially in the case of peaches, apples and pears [29,34]. Rinsing fruits and vegetables under tap water or washing with a mild soap solution has been shown to significantly reduce most pesticides, especially permethrin, because most reside on the surface [35]. Since rinsing and scrubbing produce is as effective as using mild soap, recommendations to consumers emphasize the former rather than the latter [36,37].

Parents are often concerned about safety and nutritional differences between store-bought and homemade baby foods but research evaluating them is limited. The current study attempted to address this gap by evaluating home, lab and commercial made baby foods using the same recipes. Although the source, handling and processing of the ingredients would not have been identical for the three groups of baby foods, it reflects a more realistic representation of the preparation of baby food within the home versus a commercial facility. The current study was designed as a pilot and is limited to the Canadian context and the recipes/samples analyzed. Conducting a similar study in other jurisdictions would support generalizability of the findings since other countries have different cultural preferences and regulatory environments. Replication of findings within a larger sam- pling frame and assay of additional nutrients, pesticide residues and microbes would also strengthen the current study findings and is recommended. In addition, future studies should also consider analyzing the starting raw ingredients before processing and cooking steps are performed. As mentioned earlier, differences in the source of the starting ingredients may account for the differences observed in the present study. Nevertheless, the current study provides valuable insight for infant feeding recommendations to ensure optimal nutrition and safety.

\section{CONCLUSION}

Parents may question if commercial products are inferior to homemade baby foods [38]; however, the samples examined demonstrate that both types of baby food can be safe, nutritious, and appropriate for infants. Health professionals can support the parent's choice to feed their child homemade or commercial baby food. However, when caregivers decide to prepare them at home, advice should be provided on safe food handling recommendations [36] to prevent contamination since slight negligence can lead to serious health complications for the baby. Many parents, at the end of the day may take advantage of the convenience offered by commercial foods and may consider options that have few chemicals or preservatives, and no added salt, sugar, or fillers. The key message is, when chosen wisely and handled with care, baby foods, either made at home or purchased commercially, can be part of a healthy diet for babies.

\section{ACKNOWLEDGEMENTS}

Consumer samples provided in- kind by H.J Heinz Company, Canada and the study was funded by the H.J Heinz Company Foundation, Pittsburgh, USA.

\section{DECLARATION OF INTEREST}

Dr. David Yeung provides nutrition consulting services for H.J Heinz Company Foundation and the H.J. Heinz Company, based in Pittsburgh. The remaining authors have no interests to declare.

\section{REFERENCES}

[1] Chapter for textbooks for medical students and allied health professionals. Switzerland: WHO Press 2009; pp.1-99.

[2] Meister K. Feeding Baby Safely: Facts, Fads and Fallacies. 1997; Available at: http://www.acsh.org/docLib/20040402_Feeding Baby 1997.pdf. [Accessed April 20, 2011].

[3] Kerr CM Jr, Reisinger KS, Plankey FW. Sodium concentration of homemade baby foods. Pediatrics 1978; 62(3): 331-5.

[4] Majchrzak D, Frank U, Elmadfa I. Carotenoid profile and retinol content of baby food products. Eur Food Res Technol 2000; 12(6): 407-13.

[5] Armada M, Love S, Barrett E, Monroe J, Peery D, Sobel J. Foodborne botulism in a six-month-old infant caused by home-canned baby food. Ann Emerg Med 2003; 42(2): 226-9.

[6] Louie KK, Paccagnella AM, Lior H, Francis BJ. From the Centers for Disease Control and Prevention. Salmonella serotype Tennessee in powdered milk products and infant formula--Canada and United States. JAMA 1993; 270(4): 432.

[7] Schutze GE, Sikes JD, Stefanova R, Cave MD. The home environment and salmonellosis in children. Pediatrics 1999; 103(1): E1.

[8] Mangrem CL, Leggiadro RJ. No so sunny. Pediatrics 1995; 95(5): 801-2. 
[9] Moore VK, Zabik ME, Zabik MJ. Evaluation of conventional and "organic" baby food brands for eight organochlorine and five botanical pesticides. Food Chem 2000; 71(4): 443-7.

[10] Canadian Food Inspection Agency. Nutrition Labelling Compliance Test: Appendix 4 - Laboratory Issues. Available at: http://www.inspection.gc.ca/english/fssa/labeti/nutricon/nutriconap p4e.shtml\#cont. [Accessed May 24, 2011].

[11] Health Canada. The Compendium of Analytical Methods, Volume 2, MFHPB-33: Enumeration of Total Aerobic Bacteria in Food Products and Food Ingredients Using 3M Petrifilm Aerobic Count Plates. 2001.

[12] Health Canada. The Compendium of Analytical Methods, Volume 2, MFHPB-22: Enumeration of Yeasts and Molds in Foods. 2004.

[13] Health Canada. The Compendium of Analytical Methods, Volume 2, MFHPB-34: Enumeration of E. coli and Coliforms in Food Products and Food Ingredients Using 3M Petrifilm E. coli Plates. 2001.

[14] Health Canada. The Compendium of Analytical Methods, Volume 2, MFHPB-20: Methods for the Isolation and Identification of Salmonella from Foods and Environmental Samples. 2009.

[15] Health Canada. The Compendium of Analytical Methods, Volume 2, MFHPB-21: Enumeration of Staphylococcus aureus in Foods. 2005.

[16] Health Canada. The Compendium of Analytical Methods, Volume 3, MFLP-4: Isolation and Enumeration of Bacillus cereus in Foods. 2003.

[17] Health Canada. The Compendium of Analytical Methods, Volume 2, MFHPB-23: Enumeration of Clostridium perfringens in Foods. 2001.

[18] Health Canada. The Compendium of Analytical Methods, Volume 2, MFHPB-30: Isolation of Listeria monocytogenes from All Foods and Environmental Samples. 2011.

[19] Health Canada. The Compendium of Analytical Methods, Volume 3, MFLP-8: Procedure for the Detection of VerocytotoxinProducing Escherichia coli in Food Samples. 1996.

[20] Fillion J, Sauve F, Selwyn J. Multiresidue method for the determination of residues of 251 pesticides in fruits and vegetables by gas chromatography/mass spectrometry and liquid chromatography with fluorescence detection. J AOAC Int 2000; 83(3): 698-713.

[21] Health Canada. List of Maximum Residue Limits Regulated Under the Pest Control Products Act. 2011.

[22] Stallone DD, Jacobson MF. Cheating Babies: Nutritional Quality and Cost of Commercial Baby Food. 1995; Available at: http://www.cspinet.org/reports/cheat1.html.

[23] Renwick AG. Pesticide residue analysis and its relationship to hazard characterisation (ADI/ARfD) and intake estimations (NEDI/NESTI). Pest Manag Sci 2002; 58(10): 1073-82.
[24] Codex Alimentarius Commission. Pesticides Residues in Food and Feed: Pesticide Index. Available at: http://www.codexalimentarius. net/pestres/data/pesticides/index.html\#P. [Accessed 28 ${ }^{\text {th }}$ April, 2012].

[25] Government of Canada. Fact Sheet on Pesticides and Food. 1999; Available at: http://publications.gc.ca/collections/Collection/H1132-5-1999E.pdf. [Accessed 28 ${ }^{\text {th }}$ April, 2012]

[26] Government of Canada. Pesticides and Food. Available at: http://www.hc-sc.gc.ca/cps-spc/alt_formats/pdf/pubs/pest/factfiche/pesticide-food-alim-eng.pdf. [Accessed $28^{\text {th }}$ April, 2012].

[27] Weichenthal S, Moase C, Chan P. A review of pesticide exposure and cancer incidence in the Agricultural Health Study cohort. Environ Health Perspect 2010; 118(8): 1117-25.

[28] United State Environmental Protection Agency. Oxamel Facts. USA: US. Environmental Protection Agency, Prevention Pesticides and Tox ic Substances 2000.

[29] Environmental Working Group. Metrics Used in EWG's Shopper's Guide to Pesticides Compiled from USDA and FDA Data. Available at: http://static.foodnews.org/pdf/2010-foodnews-data.pdf. [Accessed 15th April, 2011].

[30] United States Environmental Protection Agency. DCNA (Dicloran) Reregistration Eligibility Decision (RED) Fact Sheet. 2006.

[31] International Food Information Council Foundation. Pesticides And Food Safety. IFIC Review 2009 October 15, 2009.

[32] Keikotlhaile BM, Spanoghe P, Steurbaut W. Effects of food processing on pesticide residues in fruits and vegetables: a metaanalysis approach. Food Chem Toxicol 2010; 48(1): 1-6.

[33] Elkins ER. Effect of commercial processing on pesticide residues in selected fruits and vegetables. J Assoc Off Anal Chem 1989; 72(3): 533-5.

[34] Stepan R, Ticha J, Hajslova J, Kovalczuk T, Kocourek V. Baby food production chain: pesticide residues in fresh apples and products. Food Addit Contam 2005; 22(12): 1231-42.

[35] Krol WJ, Arsenault TL, Pylypiw, Harry M, Incorvia Mattina MJ. Reduction of Pesticide Residues on Produce by Rinsing. J Agric Food Chem 2000; 48(10): 4666-70.

[36] Health Canada. Safe Handling of Fresh Fruits and Vegetables. 2009.

[37] Canadian Partnership for Consumer Food Safety Education. Ask Mrs Cookwell: Washing Fruits and Vegetables. Available at: http://www.canfightbac.org/cpcfse/en/cookwell/ask/washing foods $/ \# 171$. [Accessed 24 ${ }^{\text {th }}$ May, 2011].

[38] Seaman CEA, D'Allessandro D, Swannie M. Choice of weaning foods. Br Food J 1996; 98(8): 13-6. 